\title{
Empirical Study on SPOC-Based Mixed Teaching of College English Reading and Writing
}

\author{
Min She ${ }^{1, *}$ Fei Chen ${ }^{1}$
}

\author{
${ }^{I}$ Teaching Center for General Courses, Foreign Language Teaching Department, Chengdu Medical College, \\ Chengdu, Sichuan 610500, China \\ *Corresponding author. Email: 1000233@cmc.edu.cn
}

\begin{abstract}
In order to improve students' learning predicament in English learning and enhance their reading and writing abilities, this study aims at establishing a SPOC-based mixed classroom mode for College English reading and writing teaching. The SPOC creates a high-quality online learning environment for knowledge learning and thus, more time can be allowed for classroom output activities. In this study, elaboration is conducted around four teaching phases of SPOC-based mixed teaching: SPOC online learning, offline cooperative learning, writing skill construction and prompt evaluation. Besides, an empirical study was done to prove the effect of mixed classroom design on reading and writing ability by means of control experiment and statistics analysis tool, SPSS. Research and analysis show that this design has obvious advantages in improving students' reading and writing abilities.
\end{abstract}

Keywords: SPOC-based; mixed teaching; empirical research; College English, reading and writing abilities

\section{INTRODUCTION}

\subsection{Existing Problems in Traditional English Class}

The globalization of social life and economy makes English increasingly important. As one of the most important information carriers, English has become the widestly used language in all fields of human life, and it has become an essential skill to use English. College English teaching aims at improving students' application skills. However, a frustrating phenomenon in traditional college English class has aroused much concern. Most students are found as passive learners short of interest and enthusiasm in English learning, just receiving teachers' instruction passively and taking notes down mechanically. Lack of initiative, they rarely think on their own and do initiative application, which further lead to poor English application especially writing and reading abilities. It is high time to change it.. Fortunately, technological advances provide us with a solution to the problems. English learning is a system involving knowledge acquisition and skill cultivation. New technological tools such as Internet, video conferencing and telepresence systems make out-ofclass knowledge instruction possible and thus more class time is saved for skill cultivation, which on one hand, can perfectly improve students' practical skills and on the other hand, urge students to do active learning and arouse their passion in English learning. Therefore, this study attempts to establish a SPOC-based mixed classroom teaching for college English reading and writing to spend less time in class lecturing and thus to save more time for in-class activities.

\subsection{Literature Review}

SPOC (small private online courses) is a small-scale private online course with a limited number of selected students. Mixed classroom combining online education (SPOC) and offline teaching not only ensures the completion rate of students' courses, but also solves the problem of matching curriculum setting with students' knowledge [1]

Domestic research literature shows that the comprehensive application of mixed classroom has attracted extensive attention of scholars. Jiehui $\mathrm{Hu}$ and Zhongjie $\mathrm{Wu}$ (2014) conducted a quantitative and qualitative survey to analyze students' attitudes towards the model [2]. Students generally reflect that such class has played a good role in promoting the development of language ability. Yan Jiang and others analyzed the effect of flipped classroom teaching based on SPOC with specific cases[3]. From the perspective of five negative motivations, Lin $\mathrm{Xu}$ puts forward that "SPOC + flipped classroom" can help students rebuild their autonomous learning ability, which is a new mode of Innovative Information College English teaching[4]. Wang $\mathrm{Na}$ analyzed the deconstruction of traditional classroom, and discussed the Teaching Reconstruction Based on SPOC flipped classroom[5]. Shen Ying and Sheng Yuedong (2015) adopted the flipped teaching process of "autonomous learning, cooperative learning, experience construction", forming a meaningful teaching experience[6]. It is believed that such mode would stimulate students' curiosity and learning initiative, and 
enhance their language application ability. Most of the previous studies are generally descriptive, lack of in-depth elaboration of instructional design, and less detail is given to the teaching design in reading and writing, and empirical research is even far less. Consequently, to make up for the gap, this study will explore SPOC-based mixed teaching design of reading and writing and empirically demonstrate its role in improving reading and writing abilities.

\section{IMPLEMENTATION OF MIXED CLASSROOM TEACHING IN READING AND WRITING}

Based on the flipped classroom teaching process proposed by Ying Shen and Yuedong Sheng (2015) [6], this study proposes a specific mixed teaching plan (see Figure.1) which is composed of online SPOC online learning and offline classroom activities. Offline classroom teaching further includes three phases as cooperative learning, skill construction and timely evaluation. Students first gain exposure to raw material outside the classroom on SPOC course. Then students focus on the harder work of using knowledge through discussion, teamwork and problem solving in offline classroom learning.

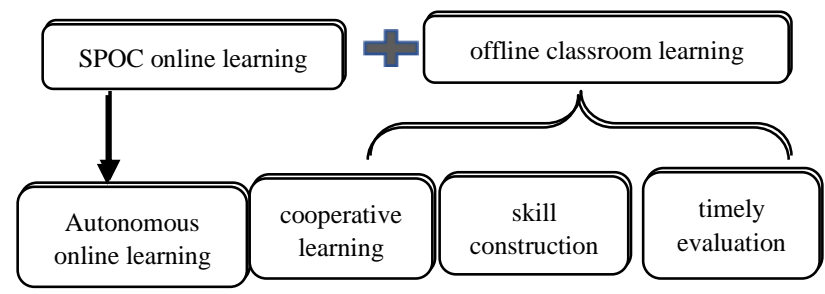

Figure 1. Mixed teaching process

\subsection{SPOC Autonomous Online Learning}

The SPOC platform is only open to students in this study, and the resources include teaching video, interactive discussion, reading test and homework. Each unit contains four videos, respectively about vocabulary explanation, discourse explanation, cultural background knowledge and celebrity quotations learning. Online Autonomous Learning should be done before offline class under the guidance of teachers. Students are required to master the words, cultural background information and sentence meanings. Effective online autonomous learning is the foundation for mixed teaching success. Therefore, it is necessary to take some measures to help students finish their autonomous learning in a high quality. Intervention involves three aspects: self-learning supervision, selflearning ability training and self-evaluation habit training.

- Supervision of autonomous learning Make full use of SPOC platform's check-in and real-time recording function to fully grasp students' learning trends. Besides study tasks issued to students before autonomous learning. are required to be completed within a specified time: summarizing the meanings, usages and sentence patterns of core words; extracting global information of the learning text. A comprehension test is also conducted to further check their learning outcomes. Students are encouraged to discuss with teachers and peers about learning difficulties on SPOC platform actively and timely.

- Cultivation of students' self-study ability. Guide students to make a learning plan according to learning objectives. They learn to decompose learning tasks; in line with the learning plan. They should also learn to reasonably allocate time for efficient completion of learning in limited time.

- Cultivation of self-evaluation habit.

Assist students to do self-evaluation on selflearning from the following aspects: timeliness of task completion; whether the learning objectives are achieved; their merits and weakness in the learning process. In order to promote better autonomous learning, students should constantly reflect on their own learning situation to take advantage of their strengths and avoid weaknesses.

\subsection{Cooperative Learning}

Cooperative learning, the first phase of offline classroom teaching, provides students chances to internalize their autonomous learning achievements. Teachers and students first discuss the common difficulties encountered in SPOC learning: the structural analysis and in-depth exploration of textual information..

- Brainstorming activity. This activity enables students to summarize the expressions of words and phrases related to the theme of the text with the purpose to sort out and systematize relevant words and expressions.

- Pragmatic situational configuration. Based on the key words and phrases, the teacher creates different pragmatic situations and asks students to choose the most appropriate words and phrases to configure the situation and use the words in sentences. In the activity, timely feedback is given on the syntactic correctness of students' language production and the accuracy of word use. It will strengthen students' learning of the pragmatic occasions of the core words and phrases and ultimately help them master the application of words in real situation, not only the memory of words spelling and pronunciation.

- Mind mapping activity On the basis of language learning, the teacher guides students to determine the topic sentences of paragraphs, to clarify development of paragraphs, and finally to draw a mind map to reveal the logical relationship among paragraphs and the supportive power of paragraphs to textual theme. Information map can make 
students clearly understand the informational organization of the discourse.

In conclusion, cooperative learning is to help students construct a bottom-up discourse analysis model: vocabulary-paragraphs-discourse, and thus improve their reading ability, which also paves the way for writing.

\subsection{Skill Construction}

As the second phase of offline activities, skill construction focuses on writing output and aims at helping students create texts on the basis of language input. Text creation refers to students' independent writing practice, that is, to use the text organization pattern obtained from reading to write their own articles. Writing practice is carried out through classroom activities both on sentential and textual level (Qiu Lin, 2020 (2))[7].

- Sentence-combing activity. In view of students' difficulty in sentence production, the activity aims to help them grasp principles for sentence generation and eventually help them produce syntactically correct sentences. The teacher first uses the core phrases and sentence patterns to make sentences, then disturbs the sentence structure, and finally asks students to reorganize the sentences according to sentence production principles.

- Rewriting activities of the discourse information. First, the teacher uses simple words and sentences to summarize the main idea of the reading text. Then students should use the new words, phrases and sentence patterns to rewrite the teacher's summary. Before rewriting, students and teacher work together to analyze and judge what new words, phrases and sentence patterns can be used as substitutes for the simple ones. This activity can increase the chances of using the new target language and further strengthen the link between the new language form and the meanings.

- Discourse creation activities. In order to stimulate students' interest in writing, the teacher does not assign named writing task, but free writing task so that students can choose freely. Students can continue or rewrite the ending of the text. They can also do critical writing about discourse idea; they can even choose to express their thoughts on any specific topic.

- To facilitate students to do better writing, following guidance are offered such as determination of the theme of the text; collection of supportive materials for the theme from different aspects; decision of the development mode of each paragraph and finally the choice of appropriate language forms to express ideas properly. Principles should be provided to students that language option should be based on the type, formality, and writing purpose of the text. Only in this way can writing achieve a harmonious unity of language form, meaning and pragmatics

Skill construction helps students understand the top-down writing preparation process: discourse--paragraph development (topic sentence + development sentence)-vocabulary, and the bottom-up writing process: vocabulary--sentence paragraph (topic sentence + development sentence)--discourse. The two processes help students improve their writing ability effectively.

\subsection{Timely Evaluation}

Timely evaluation includes feedback from both teachers and peers, consisting of self-evaluation, students' mutual evaluation and teachers' feedback. The first two are carried out on SPOC platform before class, the last one in offline class. Students' self-evaluation and mutual evaluation focus on error picking: spelling errors, word use errors, syntactic errors and textual logical errors. First, students do selfevaluation and make corrections. After self-evaluation, mutual evaluation follows which is carried out in group. Members put forward suggestions for revision and singled one out in the best quality for teachers' comments and evaluation. The teacher's feedback no longer revolves around the mistakes, but the sparkling of the composition for students to learn for reference. These assessments, in turn, contribute to the perfection of teaching design. In other words, the four stages are not static but a interdependent dynamic cycle.

\section{EMPIRACAL RESEARCH OF MIXED CLASS IN COLLEGE ENGLISH READING AND WRITING}

\subsection{Research Procedure}

This study is to find out whether the mixed teaching plan based on SPOC can effectively improve college students' English reading and writing ability. The research objects are from two freshmen classes of clinical medicine major of grade 2019 taught by the author.

\subsubsection{Pre-test of original reading and writing abilities}

The consistent admission criteria of the same major basically ensure that there is no significant difference in the basic English reading and writing ability of the objects. For further confirmation, a pretest will be conducted on the basic English reading and writing abilities by independent $t$ test. The students completed the reading and writing parts of previous CET- 4 paper within the specified time, and the scores were collected as their basic reading and writing 
ability datas on which independent sample t-test was conducted with IBM SPSS statistics software to ensure no significant difference exist in students' basic reading and writing abilities.

\subsubsection{Sampling group teaching}

One class was chosen as the experimental group with 47 students. Mixed classroom teaching was adopted. The control class with 45 students was taught with traditional teaching mode which put its emphasis on the instruction of English knowledge.

\subsubsection{Post-test of reading and writing abilities}

After 20 weeks of experimental teaching, the two groups of students took CET-4 in December 2019 to collect their reading and writing scores as the post-test data for their reading and writing abilities. Independent t-test was used to analyze and verify whether mixed instructional design can significantly improve these abilities.

\subsection{Analysis of Pre-test Result}

The independent sample t-test results of pretest data showed that no significant difference in reading and writing scores between the two groups $(t=-0.61, D F=90$, $\mathrm{P}=0.499>0.05) ;(\mathrm{t}=-0.56, \mathrm{DF}=90, \mathrm{P}=0.614>0.05)$. In other words, there is no significant difference in basic literacy between the two groups. (see Table 1).

Table 1. T-test Result of Pre-test

\begin{tabular}{|c|c|c|c|c|c|c|}
\hline & \multicolumn{2}{|c|}{$\begin{array}{c}\text { Experimental } \\
\text { Group } \\
n=47\end{array}$} & \multicolumn{2}{|c|}{$\begin{array}{c}\text { Control } \\
\text { Group } \\
n=45\end{array}$} & \multirow[b]{2}{*}{ MD } & \multirow[b]{2}{*}{$\mathrm{t}(90)$} \\
\hline & $\mathrm{M}$ & $\mathrm{SD}$ & $\mathrm{M}$ & $\mathrm{SD}$ & & \\
\hline $\begin{array}{l}\text { Reading } \\
\text { score }\end{array}$ & 159.21 & 23.45 & 162.04 & 21.13 & -2.83 & -0.61 \\
\hline $\begin{array}{l}\text { Writing } \\
\text { score }\end{array}$ & 142.06 & 15.1 & 142.62 & 13.72 & -0.56 & -0.19 \\
\hline
\end{tabular}

\subsection{Research Result: Analysis of Post-test Data}

All the students in two groups took CET4 in December 2019. Students' reading and writing scores of CET-4 were used as post-test data, and independent sample t-test was conducted by IBM SPSS statistics software. The independent sample t-test results showed that there exist a significant difference between the two groups in reading $(\mathrm{t}$ $=4.637, \mathrm{DF}=90, \mathrm{P}=0.00<0.05)$ and writing $(\mathrm{t}=4.384$, $\mathrm{DF}=90, \mathrm{P}=0.00<0.05)$. The reading and writing scores in mixed classroom are significantly higher than those in traditional classroom (MD reading $=12.16$ ), (MD writing =7.19). The analysis shows that the SPOC based flipped design of College English reading and writing can effectively improve students' English reading and writing abilities (see Table 2).

Table 2. T-test Result of Post-test

\begin{tabular}{|c|c|c|c|c|c|c|}
\hline & \multicolumn{2}{|c|}{$\begin{array}{c}\text { Experimental } \\
\text { Group } \\
n=47\end{array}$} & \multicolumn{2}{|c|}{$\begin{array}{c}\text { Control } \\
\text { Group } \\
n=45 \\
\end{array}$} & \multirow[b]{2}{*}{$\mathrm{MD}$} & \multirow[b]{2}{*}{$\mathrm{t}(90)$} \\
\hline & $\mathrm{M}$ & $\mathrm{SD}$ & $\mathrm{M}$ & $\mathrm{SD}$ & & \\
\hline $\begin{array}{l}\text { Reading } \\
\text { score }\end{array}$ & 199.51 & 12.78 & 187.36 & 12.34 & 12.16 & 4.637 \\
\hline $\begin{array}{l}\text { Writing } \\
\text { score }\end{array}$ & 166.15 & 8.2 & 158.96 & 7.5 & 7.19 & 4.384 \\
\hline
\end{tabular}

\section{RESULTS AND DISCUSSION}

The teaching practice confirms that SPOC-based mixed teaching design of College English reading and writing can significantly improve students' English reading and writing abilities. In order to give full play to its effectiveness, we should keep in mind that the change lie in not only teaching mode, also the roles teachers and students play.

First, the teacher is more an activity organizer and guider than an instructor. Teacher's main role is not instructing knowledge any longer, but instead collecting learning materials and providing opportunities and activities to guide students to think deeply and apply knowledge. Class time should be devoted to applied learning activities and more higher thinking tasks.

Secondly, students' study way and learning habit should also change. Students should be encouraged to be an initiative learner but not a passive knowledge receiver. Students should be inspired to promote a deeper understanding of online learning, and to make application and connection between the old and the new. Additionally, cultivation of students' awareness of independent study is extremely essential. In traditional classroom, students depend more on teachers than themselves to carry out study. They don't know how to do self-learning and neither do they know how to detect and solve problems in learning. And that would hinder them from doing effective online learning, so what teacher exactly should do in mixed classroom is to inform students of self-learning consciousness and strategies.

What' more, interaction way between teachers and students is also changed. Mixed classroom is student-centered classroom other than teacher-centered one. As a supporter and helper but not the authority, teachers should try to establish an equal relationship with students. Thus, students can feel free to seek support from teacher when necessary.

Finally, Students'comprehension sould be accurately analyzed and feedback students needed should be provided in the classroom in time. Diversified evaluation methods 
should be adopted. Besides, evaluation should cover the whole teaching process not only for offline classroom but also for online SPOC learning. The pre-class assignments that students completed as evidence of their preparation can also help both students and teacher to assess acquired knowledge and understanding

\section{CONCLUSION}

The research confirms that SPOC-based mixed classroom encourages active learning and skills improvement in reading and writing. SPOC system provides students with the opportunity to view and stay a variety of lectures to make English knowledge acquisition interesting and to promote students' learning autonomy and enthusiasm. In order to exert its greatest effectiveness, teachers should make the following efforts. During online learning, teachers should strengthen the guidance and supervision of students' autonomous learning, and instill self-study strategies so as to improve the students' autonomous learning ability. Cooperative learning and skill construction are the most important phases of offline classroom teaching, which directly affects the cultivation and improvement of students' English reading and writing abilities. Cooperative learning helps students deepen reading input learning, acquire the organization of paragraph and text and correct use of language knowledge. Skill construction helps students to use reading input learning in reverse to exercise writing output. Teachers should help and guide students to apply language gradually to form their own writing. It is also important to evaluate the output of students in a timely and effective way. Only by connecting each phase of mixed classroom together can we promote the internalization and application of knowledge and improve the students' reading and writing abilities. In conclusion, the benefits of SPOC enhanced mixed classroom may cause a distinct change in English learning.

\section{ACKNOWLEDGMENT}

My deepest and sincerest appreciation should firstly go to my dear colleagues, especially Xuecheng Wang and Min
She. I was inspired and provided with abundant useful materials which helped me conduct my study. Without their help and encouragement, I wouldn't have accomplished my work and finally accomplished my paper. Thank them all again!

\section{REFERENCES}

[1]L. Xiaojie, "Problems and Countermeasures of College English teaching Practice Based on SPOC and Flipped Classroom", Journal of Neijiang Normal University, No.1, pp. 84-88, 2020. (In Chinese)

[2]H. jiehui, \&W. Zhongjie, Research on the Flipped Classroom Teaching Mode of College English Based on MOOC, Audio Visual Foreign Language Teaching, No.11, pp. 40-45, 2014. (In Chinese)

[3]J. Yan, \&H. Jiasheng, Research on Large Scale Teaching Operation Mechanism of College English Flipped Classroom Based on SPOC. Audio Visual Foreign Language Teaching, No.4, pp. 9-15, 2018. (In Chinese)

[4]X. Lin, The Construction of "SPOC + Flipped Classroom" Teaching Mode Based on Negative Motivation, Foreign Language Teaching, No.5, pp. 8184, 2018. (In Chinese)

[5]W. Na, SPOC Flipped Classroom of College English: Construction of an Effective Learning Mode, No.3, pp. 52-57, 2016. (In Chinese)

[6]S Ying, \&S Yuedong, Flipped Classroom Teaching of College English Based on Inquiry Community System, Foreign Language Circle, No.4, pp.81, 2015. (In Chinese)

[7]Q. Lin, An Example Analysis of the Design Criteria of "Output Oriented Approach", Frontier of Foreign Language Education Research, No.2, pp. 12-19,89, 2020. (In Chinese) 